\title{
Nanduty
}

\section{O PRÓLOGO DA BARBÁRIE}

\section{THE PROLOGUE OF BARBARISM}

Érika de Freitas Arvelos (PPGCS/INCIS/UFU) - erikafreitasarvelos@gmail.com David Silva de Oliveira - davids.oliveira@gmail.com

\begin{abstract}
RESUMO: No ano de 2018 realizaram-se no Brasil as eleições gerais. A população brasileira votou para presidente, governadores, senadores, deputados federais, estaduais e distritais. $\mathrm{O}$ primeiro turno aconteceu no dia 7 de outubro e o segundo turno no dia 28 do mesmo mês. $\mathrm{O}$ período pré-eleitoral foi marcado por profusos acontecimentos: manifestações, assassinatos, agressões, insultos, entre outras ocorrências. Grande parte motivadas por desavenças políticas. Essas ocorrências hostis apresentam algo em comum: um circuito de sentimentos e exaltações sanhas que estavam sendo agenciadas nas redes sociais. Diante disso, nos interessa o estudo do agenciamento dessas ações (fala/escrita/ações dos corpos) durante a pré-eleição política no Brasil. Analisamos como as redes sociais e as informações que lá circulavam, sobre os candidatos à presidência, contribuíram para uma mudança cognitiva, nos padrões fenomenológicos de atenção, consciência política e história. Para tal empenho analítico utilizamos o cabedal teórico das ciências sociais (antropologia, sociologia e política), alguns conceitos de Michel Foucault, a biopolítica, assim como agenciamos outros conceitos de áreas de outras áreas do conhecimento, por exemplo: literatura, linguística e psicanálise, criando uma análise aberta, em rede, ou seja, rizomática.
\end{abstract}

PALAVRAS-CHAVE: Biopolítica, Redes sociais, Linguagem.

\begin{abstract}
In the year of 2018 the general elections were made in Brazil. The brazilian population voted for president, governors, senators, federal, state and district deputies. The first turn happened on october 7 th and the second turn on the 28th of the same month. The preelectoral period was marked by deeply events: manifestations, murders, aggressions, insults, between other occurrences. Majority motivated by political disabilities, these hostile occurrences presents something in common: a circuit of feelings and fury exaltations that were being agencyed in the social networks. Therefore, we are interested in the study of the agency of these shares (speech / writing / body actions) during political pre-election in Brazil. We analyzed how the social networks and the information that they circulated, about the candidates to the presidency, contributed to a cognitive change, in the phenomenological standards of attention, political consciousness and history. For that analytical commitment, we use the theoretical cabedal of social sciences (anthropology, sociology and political science), some concepts of Michel Foucault, biopolytics, and concepts of other areas of knowledge, for example: literature, language and psychoanalysis, creating an open analysis, in network, that is, rizomatic.
\end{abstract}

KEYWORDS: Biopolitics, Social networks, Language. 
Não exijam da política que ela restabeleça os 'direitos' do indivíduo tal como a filosofia os definiu. O indivíduo é produto de poder. O que é preciso é 'desinvidualizar' pela multiplicação e o deslocamento. O agenciamento de combinações diferentes. $O$ grupo não deve ser o liame orgânico que une os indivíduos hierarquizados, mas um constante gerador de 'desindividualização' Foucault, para uma vida não fascista

A trêmula esperança, o milagre implacável da dor e o assombro do gozosempre perdurará. Jorge Luís Borges, Inscrição em qualquer sepulcro.

\title{
ANTEATO: AS PALAVRAS, O EU E O OUTRO QUANTO TÓPICO DO IMAGINÁRIO
}

\begin{abstract}
As representações não se enraízam num mundo do qual tomaram emprestado seu sentido; abrem-se em si mesmas para um espaço que lhes é próprio e cuja nervura interna dá lugar ao sentido.

Michel Foucaul, As palavras e as coisas.
\end{abstract}

As eleições gerais do ano de 2018 são um dos marcos da história recente do Brasil. Nos últimos anos temos vivenciado intensas contradições que repercutem na insatisfação de grande parte da população com o cenário político vigente. Deparamonos com uma subversão dos sujeitos a uma dialética do desejo ${ }^{1}$. Tal gana desejante, longe de ser completamente inconsciente, resultou no envolvimento direto da população com as discussões políticas, "uma adesão social construída através das afecções" (Safatle, 2015: 16-17).

A fala, isto é, as palavras, foram utilizadas para defender com veemência certos ideais políticos e ideológicos na tentativa de solucionar problemas prementes do campo político. As palavras agenciadas nas redes sociais (produção do discurso: seja ele oral e escrito) nos levaram para o encontro da política com a corporeidade. As palavras encontram corpos.

\footnotetext{
${ }^{1}$ Desejo no sentido Freudiano do termo. Desejo (Der Wunsch); relacionado ao retorno a questões de experiência que marcaram a vida do sujeito por um traço mnêmico causado pela insatisfação, no qual precisa ser repetido para que o desejo se realize.
} 


\title{
Nanduty
}

ISSN:2317-8590

Neste artigo desvelamos parte das representações simbólicas proferidas em relação ao Outro na rede social Facebook, tendo por base relacional o discurso do então candidato à presidência Eduardo Jair Bolsonaro do Partido Social Liberal (PSL). Voltamo-nos para aquilo que agencia nossas relações, isto é, nossa comunicação: a língua(gens) e as coisas:

Cabe salientar em especial a extrema heterogeneidade dos gêneros do discurso (orais e escritos), nos quais devemos incluir as breves replicas do dialogo do cotidiano (saliente-se que a diversidade das modalidades de dialogo cotidiano e extraordinariamente grande em função do seu tema, da situação e da composição dos participantes), o relato do dia-a-dia, a carta (em todas as suas diversas formas), o comando militar lacônico padronizado, a ordem desdobrada e detalhada, o repertório bastante vario (padronizado na maioria dos casos) dos documentos oficiais e o diversificado universo das manifestações publicísticas (no amplo sentido do termo: sociais, politicas. (Bakhtin, 2016:262)

Nessa medida, foi feita uma leitura possível do uso das redes sociais como instrumento biopolítico. Interessa-nos analisar a maneira como foi articulado o vínculo e trato de identificações e correspondências pelo uso ou negação das palavras durante as eleições gerais. Como recorte de análise no uso das redes sociais, por ser um universo vasto, nos focamos apenas na rede social Facebook. A rede social Facebook ${ }^{2}$ é atualmente o site mais acessado do mundo. Mundialmente são 2,13 bilhões de usuários ${ }^{3}$. No Brasil são 127 milhões de usuários da rede ${ }^{4}$. A premissa da rede social é:

\begin{abstract}
Através de nossa rede de aplicativos e serviços, estamos construindo um tipo diferente de companhia que conecta bilhões de pessoas ao redor do mundo, dando-lhes meios de compartilhar aquilo que lhes é mais importante e ajudando a aproximar as pessoas (...). Nossa equipe global está constantemente interagindo, resolvendo problemas e trabalhando em conjunto para capacitar as pessoas ao redor do mundo a construir uma comunidade e conectar-se de forma significativa ${ }^{5}$.
\end{abstract}

\footnotetext{
2 Rede social lançada em 2004 por Mark Zuckerberg, Eduardo Saverin, Andrew McCollum, Dustin Moskovitz e Chris Hughes, estudantes da Universidade Harvard.

3 https://link.estadao.com.br/noticias/empresas,facebook-chega-a-2-13-bilhoes-de-usuarios-em-todo-omundo,70002173062. Visitado em 23 de fevereiro de 2019.

4 https://www1.folha.uol.com.br/tec/2018/07/facebook-chega-a-127-milhoes-de-usuarios-mensais-nobrasil.shtml. Visitado em 23 de fevereiro de 2019.

5 "Through our family of apps and services, we're building a different kind of company that connects billions of people around the world, gives them ways to share what matters most to them, and helps bring people closer together (...). Our global teams are constantly iterating, solving problems, and working
} 


\section{Nanduty}

ISSN:2317-8590

Durante o período eleitoral o uso das redes sociais se tornou o local das inconstâncias políticas do afeto. As publicações, isto é, as palavras, estavam eivadas com os preceitos morais característicos do período conturbado no cenário político e social. Observamos, neste período, uma confusão conceitual no cenário da discussão política envolvendo o conceito de "liberdade de expressão". A liberdade, no entanto, "significa liberdade pessoal e não está, de nenhum modo, ligada aos esforços pela igualdade ou à luta contra a violência estatal" (Butler, 2012: 21).

Verificamos a intensificação dessa participação das palavras na rede, pela relação das ações dos sujeitos sociais, que tinham por base o discurso do candidato à presidência Jair Bolsonaro, utilizado para uma afirmativa de negação da existência do Outro, daquele que é diferente. Concomitante a isto, os discursos nesse espaço apresentaram uma ausência empática dosada por uma relativização da história. No campo da linguagem a escrita digital limitou a função de comunicação e potência da própria linguagem.

Os afetos, o desejo, a insatisfação, os preceitos morais, conservadores e liberais se atravessaram de maneira abstrusa, complexificando a análise da conjuntura política que estava sendo articulada no Brasil. A dinâmica comum desse período eleitoral, tanto por parte da esquerda e da direita nos meses da eleição de 2018, foi a promoção visual/ virtual de Bolsonaro, o "Coiso" (expressão da esquerda) ou "Mito" (expressão da direita $)^{6}$, como era conhecido nas redes sociais ${ }^{7}$. Não faz parte do feitio deste artigo falar sobre o candidato, mas o uso que se fez dos seus discursos.

together to empower people around the world to build community and connect in meaningful ways." Retirado de: https://newsroom.fb.com/company-info/ em 23 de fevereiro de 2019. Tradução nossa.

${ }^{6}$ Usamos desses termos: direita e esquerda, não reforçando uma análise binária e genérica, mas como método de análise dos posicionamentos no cenário político do Brasil, bem mais abrangente.

7 As críticas eram feitas por textos curtos na timeline (linha do tempo) no Facebook, por vídeos que criticavam o candidato e seus posicionamentos (como por exemplo a música "Segredinho" lançada em março de 2018 pelo trio: Pablo Bispo, Ruxell e Sérgio Santos, do grupo intitulado Pankadon.), em formas de memes, ou em campanhas de correntes virais de hashtags (como por exemplo: \#elenão). Essa reação contrária ao candidato e seu discurso se desenhou pela reação a uma série de retrocessos políticohistóricos, mas a indignação caminhou para a mesma via do esvaziamento da palavra. Além disso, durante o período das eleições também houve mobilizações de formação política. O movimento de apoio ao candidato também engajou-se sobretudo na militância nas redes sociais, embora não justificando de maneira precisa seus posicionamentos, antes defendia-o daquilo que chamavam de "mal-entendidos" por parte da campanha de difamação que o candidato supostamente estaria sofrendo. Essas afirmativas raramente eram explicadas, contextualizadas de forma coerente. 


\title{
Nanduty
}

ISSN:2317-8590

Para viabilidade dessas análises temos o artigo organizado da seguinte maneira: no primeiro ato tecemos considerações sobre a vida social, a língua, a linguagem e a fala na construção de um "mito" para validade de um discurso de ódio ao Outro; no segundo ato, realizamos análises sobre a linguagem e a construção do poder.

\section{PRIMEIRO ATO DA TRAGÉDIA: VIDA SOCIAL, LÍNGUA, LINGUAGEM E FALA: PRODUÇÕES DE UM "MITO".}

\begin{abstract}
A linguagem? Que é a linguagem? Que é um signo? O que mudo no mundo, nos nossos gestos, em todo o brasão enigmático de nossas condutas, em nossos sonhos e em nossas doenças - tudo isso fala, e que linguagem sustenta, segundo a gramática? Tudo é significante, ou o que o é, e para quem, segundo que regras? Que relação há entre linguagem e o ser, e é realmente ao ser que sempre endereça a linguagem? Que é, pois, essa linguagem que nada diz, jamais se cala e chama "literatura"?
\end{abstract} Michel Foucault, As Palavras e as Coisas.

Há uma faca atuando nessa descrição. Uma faca moral, um bisturi intelectual tão rápido e afiado que ás vezes não se pode vê-lo agir. Parece que todas essas peças estão ali, sendo denominadas de acordo com a sua existência. [...] Quando se aplica o pensamento analítico, ou seja, à faca à experiência, sempre se perde algo. [...] Mas [...] algo também se cria. E em vez de insistir no que se perde, é importante ver também o que se cria e encarar o processo como um ciclo eterno de vida e morte, que não é bom, nem mau, apenas é. Robert Pirsig, Zen e a arte de manutenção de motociclista.

O atual cenário político no Brasil é o resultado de vários acontecimentos que antecedem as eleições gerais de 2018. "Não basta", portanto, "saber como as coisas são, é preciso saber como as coisas vieram a ser o que são" (Lévi-Strauss, 1975: 21). Insatisfeitos com o mandato de 13 anos do Partido dos Trabalhadores, parte da população brasileira não estava se sentindo representada com a atual conjuntura política, ansiando por mudanças. Os anos precedentes foram de intenso descrédito da esfera da representação política através de denúncias de corrupção e delações envolvendo inúmeros partidos através de extorsões, subornos, propinas, lavagem de dinheiro, doações ilegais a campanhas.

Criou-se no imaginário coletivo uma ideia esvaziada do que é a política, e diante de tal desamparo surge a candidatura de Jair Bolsonaro. Capitão da Reserva Militar, político de tendências conservadoras, o parlamentar notabilizou-se por declarações 


\section{Nanduty}

ISSN:2317-8590

polêmicas e agressivas, alçando o seu nome para além do nicho militar, bancada que representava. Com a candidatura de Bolsonaro à presidência da República criou-se o imaginário do político outsider que, apesar dos 27 anos de parlamento e somente dois projetos de lei aprovados (PL 2514/1996 e PL 4639/2016), apresentava-se como uma renovação diante da crise que os partidos políticos enfrentavam. Parte da população encontrou no capitão reformado o modelo do bom candidato, defensor dos valores da família, homem de fé, nacionalista, relacionando religião e política fortemente no lema "Brasil acima de tudo, Deus acima de todos". Portanto, três características moralmente fortes para parte da população que aderiu ao discurso da mudança via candidatura do ex-militar: patriotismo, defensor do modelo de família burguês e tradicional, e religiosidade.

Para compreender, ou melhor, tentar entender de maneira radical o arranjo significativo entre o discurso de Bolsonaro ser a base representante do discurso de parte da população, torna-se importante falar sobre as seguintes questões: vida social, a língua e a linguagem para produção de sentido, satisfação do desejo e como se deu uma produção de um "mito". Primeiramente, iniciaremos nossa análise nos voltando à condição de se viver em sociedade e a dinâmica dessas relações, para que assim, diante dessas reflexões, possamos dar continuidade à análise subsequente, a produção de um mito.

Sabemos que "a sociedade é uma condição universal exclusiva da vida humana" (Castro, 2003: 297, grifo no original) cujas manifestações estão voltadas a duas questões, a primeira seria biológica, ou seja, instintual, a título de exemplo a fala. Que na reflexão bakhtiniana, trata-se de uma compreensão da fala viva, isto é, de um enunciado vivo, no qual, sua natureza é ativamente responsiva, mesmo que o grau desse ativismo seja múltiplo; afinal "toda compreensão é prenhe de resposta, e nessa ou naquela forma a gera obrigatoriamente: o ouvinte se torna falante." (Bakhtin, 2016:271). A segunda está voltada aos símbolos morais, portanto institucional. Frente a essas duas questões a sociedade é algo básico, mas não exclusivo da natureza humana, uma vez que:

Somos geneticamente predispostos à vida social; a ontogênese somática e comportamental dos humanos depende da interação com seus semelhantes; a filogênese de nossa espécie é paralela ao 


\section{Nanduty}

ISSN:2317-8590

desenvolvimento da linguagem e do trabalho, capacidades sociais indispensáveis à satisfação das necessidades do organismo. [...] A noção de 'regra' pode ser tomada pelo sentido moral e prescritivoregulativo (como no estrutural-funcionalismo) ou cognitivo e descritivo-constitutivo (como no estruturalismo e na antropologia simbólica); apesar desta importante diferença, em ambos os casos a ênfase nas regras exprime o caráter instituído dos princípios da ação e da organização sociais. [...] sujeitos que são simultaneamente criadores e criadoras do mundo das regras. (Viveiros de Castro, 2003: 297-298)

Isso significa que o processo de se tornar humano é a um só tempo instintual e institucional. Prova disso é a linguagem humana, simultaneamente composta pela capacidade biológica de emitir sons articulados e a capacidade cultural de, por meio desses sons, constituir, criar, arranjar, relacionar significados. A linguagem é multiforme e heteróclita, isto é, ela possui e pode ser expressa por diferentes domínios, sendo ao mesmo tempo física, fisiológica, social, cultural e psíquica. A língua(gem) possui duas características fundamentais: o seu domínio individual e social; que se sobrepõe simultaneamente. No domínio individual a linguagem se expressa a partir do agenciamento dos significados (códigos linguísticos) atribuídos e agenciados pelo sujeito. No domínio social, os símbolos do grupo ou de uma determinada sociedade (construções coletivas morais) passam a ser compartilhadas. Isto significa que a linguagem é ao mesmo tempo individual e social: “A própria questão da língua nacional na linguagem individual e, em seus fundamentos, o problema do enunciado (porque só nele, no enunciado, a língua nacional se materializa na forma individual)" (Bakhtin,2016:266). A título de exemplo o discurso de Bolsonaro transita entre esses dois polos da linguagem: individual, preceitos morais e sociais proferidos por ele; bem comum da população, pelo compartilhamento desses preceitos. O problema é que, ao que parece, seu discurso está aparentemente mais ligado à fala individual do que ao domínio social.

Afirmamos isso tendo por base que a linguagem é parte, produto e condição da cultura. Ela organiza, diferencia e ressignifica as relações sociais, isto é, os instrumentos, instituições sociais, sistema de valores estéticos, morais, políticos e religiosos (Lévi-Strauss, 1975). Nesse sentido, podemos afirmar que: 


\section{Nanduty}

os códigos fundamentais de uma cultura - aqueles que regem sua linguagem, seus esquemas perceptivos, suas trocas, suas técnicas, seus valores, a hierarquia de suas práticas - fixam, logo de entrada, para cada homem, as ordens empíricas com as quais terá de lidar e nas quais se há de encontrar. (Foucault, 1996:16)

Contudo, o homem é um animal social, que não se faz no isolamento. Existem, portanto, coletividades que se afirmam mutuamente pelos símbolos a eles compartilhados pela linguagem no seu processo de significação. A linguagem é um fenômeno social. A mesma é a própria condição da cultura, um conjunto simbólico de significações. (Lévi-Strauss, 1975).

No que diz respeito a esse processo de significação dos sujeitos sociais será Foucault que atualizará essas discussões. Segundo o teórico, para traduzir o sentido de uma fala, isto é, a linguagem de um povo ou cultura, é necessário entender suas representações. E para isso é imprescindível entender o sentido estrito de que "a linguagem representa o pensamento como o pensamento representa a si mesmo" (Foucault, 1996:107). Dito isso, "não há como constituir uma linguagem ou para animála por dentro, um ato essencial e primitivo de significações, mas tão-somente, no coração da representação", isto significa que a linguagem não pode ser analisada dentro de um sistema simbólico fragmentado sem relação com o processo do constructo social, pois "esse poder que ela detém de representar a si mesma, isto é, de analisar em se justapondo, parte por parte, sob o olhar da reflexão e de delegar, ela própria, num substituto que a prolongue." (Foucault, 1996:107-108).

Essas são considerações básicas para entender o processo de funcionamento dessas representações e de que para compreendê-la é necessário um percurso mais denso. E como estamos focados em tecer observações sobre as palavras agenciadas por parte da população brasileira nas redes sociais sobre o discurso de Bolsonaro durante a eleição de 2018 em relação ao uso da sua fala, é preciso um olhar atencioso.

[...] um olhar desavisado bem poderia aproximar algumas figuras semelhantes e distinguir outras em razão de tal ou qual diferença: de fato não há, mesmo para a mais ingênua experiência, nenhuma similitude, nenhuma distinção que não resulte de uma operação precisa e da aplicação de um critério prévio. Um "sistema dos elementos" - uma definição dos segmentos sobre os quais poderão aparecer as semelhanças e as diferenças, os tipos de variação de que esses segmentos poderão ser afetados, o limiar, 


\section{Nanduty}

\section{ISSN:2317-8590}

enfim, acima do qual haverá diferença e abaixo do qual haverá similitude - é indispensável para o estabelecimento da mais simples ordem. A ordem é ao mesmo tempo aquilo que se oferece nas coisas como sua lei interior, a rede secreta segundo a qual elas se olham de algum modo umas às outras e aquilo que só existe através do crivo de um olhar, de uma atenção, de uma linguagem; e é somente nas casas brancas desse quadriculado que ela se manifesta em profundidade como já presente, esperando em silêncio o momento de ser enunciada. (Foucault, 1996:15)

Esta prescrição de uma ordem entre relação e representação vai além de um sistema simbólico, pois há uma nova maneira de gerir os corpos, isto é, um novo jeito de fazer uma política da vida. Nos termos de Foucault, pertence ao biopoder biopolítica. "Trata-se de uma biopolítica porque os novos objetos de saber, que se criam 'a serviço' do novo poder, destinam-se ao controle da própria espécie; e a população é o novo conceito que se constrói para dar conta de uma dimensão coletiva" (Danner, 2010:53). Em nossa análise essa nova maneira de controle dos corpos pode ser analisada pelas redes sociais.

Por isso, nossa proposta inicial é a de estabelecer uma análise aberta em rede que estabeleça uma investigação ampla dessas mudanças, sobre a gestão dos corpos e as redes sociais, para validar argumentações de que se trata de um mecanismo de poder, pois elas se dão, ou melhor, são formadas na "fronteira" no "entre-lugar" (Bhabha.1998). Podemos pensar o encontro desse "entre-lugar" como um encontro nas redes sociais. Nesses locais o espaço cultural e político é negociado dentro de um novo arranjo histórico-cultural:

O trabalho fronteiriço da cultura exige um encontro com "o novo" que não seja parte do continuum de passado e presente. Ele cria uma ideia do novo como ato insurgente de tradução cultural. Essa arte não apenas retoma o passado como causa social ou precedente estético, ela renova o passado, prefigurando-o como um "entrelugar" contingente, que inova e interrompe a atuação do presente. O "passado-presente" torna-se parte da necessidade, e não da nostalgia, de viver. (Bhabha,1998:27)

O conceito de fronteira, portanto, designa um arranjo complexo que se forma em um momento de trânsito, onde "o espaço e o tempo se cruzam produzindo figuras complexas de diferença e identidade, passado e presente, interior e exterior, inclusão e exclusão, trata-se de um movimento exploratório incessante no entre-lugar'. (Bhabha, 


\section{Nanduty}

ISSN:2317-8590

1998:19). Dessa forma, podemos fazer a leitura de que existe uma combinação de características culturais que passam a ser manipuladas por outros indivíduos identificadoras de si nesse entre-lugar (redes sociais).

Nesse local de encontro (Facebook), observamos que existe um distanciamento do elemento diacrônico (histórico), pois os "entre-lugares" fornecem o terreno para a elaboração de estratégias de subjetivação - singular ou coletiva - que dão início a novos signos de identidade e postos inovadores de colaboração e contestação, no ato de definir a própria ideia de sociedade (Bhabha, 1998:20). Sendo, portanto, o início de formação de novos signos.

Devemos dar a devida atenção a essa nova dinâmica de produção cultural, pois elas não são estáticas, fixas, imutáveis, mas são históricas e mutantes. E isso se torna ainda mais importante quando estamos passando por um período de crise humanitária. Sendo necessário romper com a visão dualista (direita e esquerda), entendendo que esse é apenas um modelo para explicar diferenças, mas essa leitura não pode estar acoplada para explicar o real, separando nós e eles.

Voltando para a discussão salutar deste artigo, diante das teorias até aqui articuladas, observamos que dentre as inúmeras acusações e ações que circunscrevem vários corpos há uma crise no uso das palavras, isto é, da língua e da linguagem, no seu sentido amplo, quando nos voltamos às redes. Podemos identificar isso na própria produção de um "mito". O Brasil (sobretudo durante o período de consolidação do Estado-nação) criou vários mitos: mito das três raças, o mito fundador, o mito da independência, entre outros.

No ano de 2018, criou-se no imaginário brasileiro um novo mito no sentido figurado do termo. $\mathrm{O}$ conceito mito passou a ser utilizado nas redes sociais no sentido metonímico do termo, isto é, figura de retórica que consiste no uso de uma palavra fora do seu contexto semântico. Bolsonaro era considerado o "mito que virou mito que é o mito". O que fica é: que tipo de produções e efeitos de sentidos se estava sendo atribuindo às palavras dentro do contexto político?

Observamos até aqui que estamos também passando por uma crise da linguagem, se identificamos isso nas relações significativas atribuídas pelo uso das palavras, podemos constatar que são expressões vazias de sentido que promovem 


\section{Nanduty}

ISSN:2317-8590

leituras desconectadas do real. Se Bolsonaro virou mito, nos resta indagar: o que esse "mito" está contando? Ou o que o mito nos diz (metonimicamente falando)?

Aqui, precisamos ficar atentos, pois utilizamos a palavra mito fazendo uma analogia ao seu significado antropológico para tecer algumas análises com o atual presidente da República e mito análogo ao discurso fictício do real, onde figuras "fantásticas" ganham cena no cenário político, ou seja, transitamos entre metonímia e metáfora. Para que fique mais claro ao leitor, quando utilizarmos "mito" com aspas estaremos nos referindo à leitura que se faz do presidente da república e mito sem aspas ao entendimento de mito no seu sentido Levistraussiano.

Depois dessa breve observação, voltamos à nossa pergunta inicial: o que o "mito" nos diz? "O erro da ditadura foi torturar e não matar" (entrevista à rádio Jovem Pan, em junho de 2016); "Não pode o pai chegar em casa, encontrar o Joãozinho de 6 anos de idade, brincando de boneca por influência da escola" (entrevista ao programa Roda Viva em julho de 2018); “Os portugueses nem pisavam na África, os próprios negros que entregavam os escravos", "Que dívida histórica é essa que temos com os negros?" (entrevista ao mesmo programa Roda Viva); "Não fui maldoso quando disse que um quilombola que pesava 7 arrobas não serve nem para procriar" (frase dita no programa Roda Viva, refere-se ao comentário pelo qual Bolsonaro foi condenado por racismo); "Seria incapaz de amar um filho homossexual. Prefiro que um filho meu morra num acidente do que apareça com um bigodudo por aî" (Jair Bolsonaro em entrevista na revista Playboy); "Não te estupro porque você não merece" (Jair Messias Bolsonaro para a deputada federal Maria do Rosário); "Pinochet devia ter matado mais gente" (Bolsonaro sobre a ditadura chilena de Augusto Pinochet); "Eu não corro esse risco, meus filhos foram muito bem educados" (Bolsonaro para Preta Gil, sobre o que faria se seus filhos se relacionasse com uma mulher negra ou com homossexuais); "A PM devia ter matado 1.000 e não 111 presos" (Bolsonaro, sobre o Massacre do Carandiru); "Não vou combater nem discriminar, mas se eu ver dois homens se beijando na rua, vou bater" (Afirmação de Jair Bolsonaro após caçoar de FHC sobre este segurar uma bandeira com as cores do arco-íris); "Você é uma idiota, você é uma analfabeta, está censurada!" (Declaração de Jair Bolsonaro ao ser entrevistado pela repórter Manuela Borges - a jornalista decidiu processar o deputado após os ataques); "Parlamentar não deve andar de ônibus". (Declaração publicada pelo jornal O Dia em 


\title{
Nanduty
}

ISSN:2317-8590

2013); "Mulher deve ganhar salário menor porque engravida" (Bolsonaro justificou a frase: "quando ela voltar [da licença-maternidade], vai ter mais um mês de férias, ou seja, trabalhou cinco meses em um ano").

O motivo de descrever algumas dessas inferências é o de compreender a relação representativa desse discurso em uso nas redes. O problema se torna ainda maior quando as ações articuladas pelo discurso do Outro que também é o reflexo do nosso discurso, ganha força de tal maneira que passa a desejar e agir (ação do corpo) na eliminação do Outro - o diferente de mim. Quando as ideias afloram de maneira irresponsável, as palavras já não comunicam trocas históricas, políticas e de afeto humanitário, mas as ações ganham uma nova característica: a violência direcionada aos corpos, ao extermínio do corpo. Um exemplo disso é a morte do mestre de capoeira Moa do Katendê por causa de desavenças políticas no ano de 2018 - por ser contrário ao candidato à presidência Eduardo Jair Bolsonaro.

Portanto, é explícito que a identificação que ganhou corpo com os vídeos que circulavam de Bolsonaro nas redes sociais começaram a ganhar adeptos, com atitudes que chegaram a um nível de violência extrema, o assassinato. Diante disso o candidato se posicionou argumentando:

\begin{abstract}
"Pô, cara! Foi lá pergunta essa invertida... quem tomou a facada fui eu, pô! O cara lá que tem uma camisa minha, comete lá um excesso. O que eu tenho a ver com isso? Eu lamento. Peço ao pessoal que não pratique isso. Eu não tenho controle sobre milhões e milhões de pessoas que me apoiam", disse o candidato. (Declaração publicada pelo G1 em 10 de outubro de 2018)
\end{abstract}

Diante dessas questões de identificação podemos fazer a leitura que o "mito" agencia sentimentos e afetos pela desqualificação do Outro (em seus vídeos antigos). O "mito" articula e joga com o desejo dos Outros - população. O "mito" fantasia o que é real. Nesse sentido, o "mito" despertou em uma parcela significativa da população pensamentos que lhe são desconhecidos conscientemente, ou deu vazão para a ação de ações violentas. Portanto, o "mito" desperta pensamentos que lhe são aparentemente desconhecidos. A única regra que vale para esses dois conceitos "mito" com aspas e mito sem aspas é que ambos provêm da linguagem. Nesse sentido, podemos afirmar, as redes sociais provocam sérias influências no controle da subjetividade. 


\section{Nanduty}

ISSN:2317-8590

Todo esse processo de identificação com um discurso ilustra aquilo que Jamie Hecker (2012) nos chamou atenção, há uma fala contra corpos inscritos como propenso de violação: "corpos de mulheres, corpos queer, corpos escuros, corpos criminosos, corpos insanos, corpos indígenas, corpos pobres, corpos sem teto, corpos indocumentados, corpos de animais e todas as incontáveis maneiras em que essas inscrições se cruzam?”. Eliane Brum nos dá a resposta: estamos em uma crise da palavra. A questão que fica é que as palavras são constituídas por um campo de significação e de ações:

Quando tudo pode ser dito, nada mais diz. As palavras, no Brasil, se tornaram palavras fantasmas, porque nada movem. [...] Se as palavras se tornam cartas extraviadas, cartas que não chegam ao seu destino, o diálogo é interditado, e o ódio se instala. [...] Veem, mas não veem. Ouvem, mas não escutam. [...] Sem diálogo, as palavras perfuram os corpos. É urgente que as palavras voltem a dizer no Brasil - ou elas serão cada vez mais balas perdidas. E sabemos que balas perdidas acham corpos. (Brum, 2018: s/p)

No atual cenário político, essas afirmativas ganharam espaço, casa, cor, ação; invadiram os lares, comércios, universidades, famílias, pois fez sentido para alguns. O "mito" conseguiu contar sua história, com sua fala, conseguiu mobilizar uma série de questões caras para a população brasileira. Por meio da bricolagem, agenciou história, angústias, emoções e desejos. Criou-se, portanto, uma história fantasiosa de que por meio dessas ações (apresentadas por ele em suas frases aqui descritas) vamos mudar "isso que tá aí" para usar a "ideia - meio e solução" dada pelo atual presidente sobre os "problemas" que assombram o Brasil. O que não prestamos atenção é que o "mito" criado e os preceitos por ele defendidos podem parecer para alguns algo absurdo, arbitrário, sem significado, mas apesar de tudo elas sempre reaparecem a toda parte, tem ganhado força no cenário mundial e se intensificado com o uso das redes sociais.

\section{SEGUNDO ATO DA TRAGÉDIA: LINGUAGEM E PRODUÇÃO DE SENTIDOS - PODER}

Para conhecer a alma de um povo, nada melhor que conhecer sua língua. Victor Klemperer, LTI: A linguagem do Terceiro Reich. 


\section{Nanduty}

ISSN:2317-8590

O poder está diretamente relacionado com a linguagem. Notamos ao longo do artigo que as palavras, o agenciamento do discurso voltado para o Outro pela escrita e fala virtual nas redes sociais, promoveram uma série de mudanças no cenário político. Além disso, consequentemente na cognição e percepção do que é real, do que é humanitário, do que é diferente. Todas essas questões, no atual cenário político, estão relacionadas ao poder.

Temos a ilusão de que com o advento das redes sociais há uma expansão da palavra escrita e falada por se tratar de uma plataforma sofisticada de comunicação, mas o que não percebemos é que estamos em um paradoxo, isto é, em uma contradição aparente. O local de expansão da comunicação e conexão dos sujeitos sociais vem se mostrando o local do enfraquecimento das palavras e consequentemente dos vínculos sociais e de afeto. É inegável que há o esvaziamento e crise das palavras, assim como o controle político dos corpos com o uso das redes sociais foi reforçado nas eleições gerais de 2018.

Os meses sombrios e de grande instabilidade da população se intensificaram quando Jair Bolsonaro, mesmo se negando a participar dos debates, utilizou das redes sociais para se comunicar com a população. Isso permitiu leituras múltiplas e confusas. Diante disso, os sujeitos sociais, freneticamente, começaram a compartilhar suas falaspressupostos morais e políticos, incorporando e absorvendo o que se pronunciava.

Voltar ao discurso do presidente nos vídeos disponíveis na internet foi importante para compreender o longo processo de crise da população sobre o entendimento histórico, pois "é na palavra isolada que se vê a forma de pensar de uma época, o pensamento geral no qual aquele indivíduo se insere, deixando-se influenciar ou mesmo guiar'" (Klemperer, 1947:237). Além disso, outra questão que nos ajuda a pensar sobre o uso da palavra durante esse período eleitoral no Brasil é a maneira como foi empregada o seu uso, que eventualmente se tornou mecânico. Quando as palavras passam a ser empregadas em modo automático, inconsciente e involuntário, seu signo sofre um distanciamento significativo em relação ao real.

Como resultado desse processo se criou e reforçou cisões, para usar um termo de Foucault. E isso acontece pelo fato das palavras estarem diretamente ligada ao poder, e de seu uso mecânico que provêm da manipulação das ferramentas de poder: 


\section{Nanduty}

Quando o uso mecanizante da língua se estende diretamente à pessoa, é claro que esse uso procura alcançar também os objetos mais próximos, mas que estão fora de seu âmbito. Não existe mais nada que não possa ser anlaufen [posto em funcionamento], que não possa ser recondicionado, como se faz a revisão de uma máquina depois de um longo período de operação ou de um navio depois de uma longa viagem; não há nada que não se possa hineinschleusen [introduzir] ou herausschleusen [extrair], e naturalmente - oh!, linguagem do Quarto Reich nascente - não há nada que não se possa aufziehen [acionar]. (Klemperer, 1947:247 - Grifos do autor)

Podemos, mediante a citação, estabelecer alguns parâmetros com o que aconteceu no Brasil durante as eleições de 2018. O uso mecânico das palavras, seja para uso de um preceito moral, ou para negação de um regime político e até mesmo para proteção de uma nova política de estado, podem se perder na mecanização da palavra. E ao que parece foi isso que aconteceu. Uma das grandes confusões do seu uso se deu para aqueles que se intitulam de "esquerda" ou de "direita". A ação comum entre contrários e favoráveis foi o ataque direto ao Outro. Essa tentativa de desqualificação busca "não enaltecê-lo, mas isso não exclui (ao contrário!) torná-la mecanizada." (Klemperer, 1947: 242). Afinal, de maneira análoga aos pressupostos de Klemperer, parece que:

Essa estrutura oculta confere um ar de normalidade ao processo de escravização e despersonalização do qual provém a multiplicação de termos [...] oriundos da tecnologia, além de uma profusão de palavras mecanizantes. Não me refiro ao aumento de expressões especificamente técnicas que as línguas dos países civilizados experimentam desde o início do século XIX, como consequência da difusão da técnica e da sua crescente importância na vida de todos. Refiro-me à extrapolação de expressões técnicas para áreas que não são técnicas, nas quais adquirem um efeito mecanizante. Raramente aconteceu algo assim na língua alemã antes de 1933. (Klemperer, 1947:247)

O uso da linguagem, no Brasil, oriundas da tecnologia, no período político, ora parece limitada, ora não, pois há uma relação narcísica de ideal de "eu" por parte da população que estava tomada pela desolação do cenário político, por isso a aproximação com o discurso do presidente. A origem desse uso excessivo, carregados de sentidos 


\section{Nanduty}

ISSN:2317-8590

desumanos, nas redes sociais, aparentam ter uma ampla relação com a divulgação dos vídeos do presidente.

Nesse momento o uso da língua, da fala, da linguagem e consequentemente a própria análise que se fazia do cenário político, dos afetos, se distanciou do racional e passou a ser agenciada pelo desejo - fantasia do real. Por mais que na grande parte do discurso do presidente as palavras fossem direcionadas para as minorias sociais, voltouse para ele todos os holofotes: "o passo decisivo para a mecanização linguística da vida ocorre quando a metáfora técnica se aplica diretamente a alguém" (Klemperer, 1947:243).

A fala (linguagem individual) e a linguagem (códigos coletivos) podem ser considerados formas de poder. É importante chamar atenção de que a análise dos mecanismos do poder não trata de uma teoria geral do que é o poder (Foucault, 1996). O poder "não é uma parte, nem mesmo um início dela. [...] trata-se simplesmente de saber por onde isso passa, como se passa, entre quem e quem, entre que ponto, segundo quais procedimentos, e com quais efeitos" (Foucault, 1996:3-4).

Logo, só poderia ser, no máximo, e só pretende ser, no máximo, um início de teoria, não do que é o poder, mas do poder, contanto que se admita que o poder não é, justamente, uma substância, um fluido, algo que decorreria disto ou daquilo, mas simplesmente na medida em que se admita que o poder é um conjunto de mecanismos e de procedimentos que têm como papel ou função e tema manter - mesmo que não o consigam - justamente o poder. É um conjunto de procedimentos, e é assim, somente, assim que se poderia entender que a análise dos mecanismos de poder dá início e algo como uma teoria do poder. [...] Os mecanismos de poder são parte intrínseca de todas as relações, são circularmente o efeito e a causa delas, mesmo que, é claro, entre os diferentes mecanismos de poder que podemos encontrar nas relações de produção, nas relações familiares, nas relações sexuais, seja possível encontrar coordenações laterais, subordinações hierárquicas, isomorfismos, identidades ou analogias técnicas, efeitos encadeados que permitem percorrer de uma maneira ao mesmo tempo lógica, coerente e válida o conjunto dos mecanismos de poder e apreendê-lo no que podem ter específico num momento dado, durante um período dado, num campo dado. (Foucault, 1996:4-5) 


\section{Nanduty}

ISSN:2317-8590

O estudo desses mecanismos de poder também pode se articular, por exemplo, com a história das transformações econômicas, sociais, políticas, culturais, no caso brasileiro, com o uso das redes sociais:

"A análise dos mecanismos de poder, essa análise tem, no meu entender, o papel de mostrar quais são os efeitos de saber que são produzidos em nossa sociedade pelas lutas, os choques, os combates que nela se desenrolam, e pelas táticas de poder que são os elementos dessa luta" (Foucault, 1996:5).

Em relação ao discurso imperativo do presidente, "o discurso imperativo que, na ordem da teoria, consiste em dizer 'goste disto, deteste aquilo, isto é bom, aquilo é ruim, seja a favor disso, cuidado com aqui'" (Foucault, 1996:5) já se tratava de um uso abusivo do poder. Exemplo disso é o seu posicionamento e ódio contra os homossexuais e contra os povos originários no e do Brasil. Todo esse discurso que alguns caracterizam como discurso de ódio, é um discurso estético que apenas possui fundamento de ordem estética, como é o caso de seus primeiros discursos:

Quanto ao discurso imperativo que consiste em dizer 'lute contra isto e desta ou daquela maneira', pois bem, parece-me que é um discurso bem ligeiro, quando é feito a partir de uma instituição qualquer de ensino ou, até, simplesmente norma folha de papel. Como quer que seja, a dimensão do que se tem a fazer só pode aparecer, parece-me, no interior de um campo de forças reais, isto é, um campo de forças que nunca um sujeito falante pode criar sozinho e a partir da sua palavra; é um campo de forças que não se pode de maneira nenhuma controlar nem fazer valer no interior desse discurso. (Foucault, 1996:5)

Até aqui podemos ver de maneira menos turva o quanto o posicionamento do presidente pelo uso e negação das palavras possibilitou um leque de leituras de seus posicionamentos (sobretudo de seus vídeos mais antigos que segundo ele não o representavam no tempo presente).

Para encerrar nossas discussões, uma possível leitura é a de que as palavras encontram corpos em um cenário de anomia social, de frustrações, onde os afetos são articulados nas redes sociais, o discurso perdeu parte de sua potência de transformação do agente que a utiliza, e se tornou uma força representativa de frustrações confusas que é direcionada ao Outro (o culpado). Isso acontece nas redes onde tudo pode ser dito e onde informações falsas são tidas como verdadeiras (o caso das Fake News); diante 


\section{Nanduty}

ISSN:2317-8590

disso, "cabe a nós por conseguinte saber que campos de forças reais tomar como referência para fazer urna análise que seja eficaz em termos táticos" (Foucault, 1996:6).

Agamben em Homo Sacer (2010) aproxima-se do conceito de biopolítica de Foucault. Sua leitura sobre a ontologia do poder soberano está relacionada ao que é arcaico, isto é, desde que nasce o poder soberano ele é constituído sobre um segredo: "a vida nua": O Direito Romano - A figura do Homo Sacer para os gregos - vida privada se dividia entre a Zoé - vida natural e a Bios - Vida qualificada (pólis) ligada ao viver bem. Onde as pessoas conseguem distinguir o bem do mal, o justo do injusto (coisas que os animais não conseguem distinguir). A pólis nasce da negação da zoé - limite da política. Isso significa que toda política moderna se assenta não na bios mas na zoé Estado territorial para Estado de população (Estado moderno). Na modernidade se instaura a animalização do homem pelo fato da política estar centrada na vida nua despida de qualquer colocação. O ingresso da zoé na esfera da pólis é a razão da armadilha. Por isso produzimos ao longo do século XX os "enigmas" que ainda permanecem atuais (o nazismo, por exemplo).

"Por milênios, o homem permaneceu o que era para Aristóteles: um animal vivente e, além disso, capaz de existência política; o homem moderno é um animal em cuja política está em questão a sua vida de ser vivente" (Foucault, 1976:127). Isto é, “o 'limiar de modernidade biológica' de uma sociedade que se situa no ponto em que a espécie e o indivíduo enquanto simples corpo vivente torna-se a aposta que está em jogo nas suas estratégias políticas” (Agamben, 2010:11). Há, portanto, uma animalização do homem colocada em prática pelos sofisticadíssimos mecanismos de poder:

Somente em um horizonte biopolitico, de fato, será possível decidir se as categorias sobre cujas oposições fundou-se a política moderna (direita/esquerda; privado/público; absolutismo/democracia etc.), e que foram progressivamente esfumando a ponto de entrarem hoje numa verdadeira e própria zona de indiscernibilidade, deverão ser definitivamente abandonadas ou poderão eventualmente reencontrar o significado que naquele próprio horizonte haviam perdido. (Agamben, 2010:12)

Diante dessas questões nesse período de eleição no Brasil com a polarização entre direita/esquerda ocorreu a politização da vida nua. Em uma democracia fragilizada 


\section{Nanduty}

ISSN:2317-8590

deu abertura para um regime político com traços totalitários, afundado numa armadilha. Essa prerrogativa se torna mais presente em um Estado de exceção com a suspensão de algumas leis. Fato este que torna a leitura desse período histórico mais complexa, pois a estratégia política parece ser a de confundir a população, que já está bem confusa, e de esvaziar o sentido da história a tornando abstrata, vaga e distante do real.

Essas mudanças criam novos arranjos, junto com os velhos existentes, E com isso abre-se o espaço para as construções e possibilidades de embates sociais mais violentos, complexos e confusos nos entre-lugares das redes sociais. Não é do nosso interesse pensar essas transformações no nível da política, mas a partir dos mecanismos de poder, isto é, das tecnologias de poder.

Foucault nos mostrava que nos séculos XVII e XVIII novas técnicas de poder surgiram voltadas para o corpo, o corpo individual. Todas essas mudanças e procedimentos, aqui nos referindo a essa configuração social e as redes sociais como mecanismo de poder que "assegurava a distribuição espacial dos corpos individuais (sua separação, seu alinhamento, sua colocação em série e em vigilância) e a organização, em tomo desses corpos individuais, de todo um campo de visibilidade" (Foucault, 1996:288).

Nesse universo paralelo onde os clicks e os comentários foram o espaço de agenciamento de ideias, construções de afeto, divergência, campanha política (lives), havia uma organização dos corpos individuais onde sua voz pudesse ser escutada, tratase de maneiras de se gerir o corpo, as relações políticas e de poder. Retomando Foucault, conferimos essa leitura de que:

Eram também as técnicas pelas quais se incumbiam desses corpos, tentavam aumentar-lhes a força útil através do exercício, do treinamento, etc. Eram igualmente técnicas de racionalização e de economia estrita de um poder que devia se exercer, da maneira menos onerosa possível, mediante todo um sistema de vigilância, de hierarquias, de inspeções, de escriturações, de relatórios: toda essa tecnologia, que podemos chamar de tecnologia disciplinar do trabalho. Ela se instala já no final do século XVII e no decorrer do século XVIIII. (Foucault, 1996:288)

Na segunda metade do século XVIII, outra tecnologia de poder é criada (Foucault, 1996). Trata-se de uma tecnologia de poder que não exclui a primeira, isto é, 


\section{Nanduty}

ISSN:2317-8590

nos dizeres do autor, ela não elimina a técnica disciplinar dos corpos, mas a complementa e a modifica parcialmente, pois possui uma técnica disciplinar prévia. Em nossa leitura essa disciplina dos corpos nas redes sociais "tenta reger a multiplicidade dos homens na medida em que essa multiplicidade pode e deve redundar em corpos individuais que devem ser vigiados, treinados, utilizados, eventualmente punidos" (Foucault, 1996:209). No caso da nova tecnologia que também está relacionada com a multiplicidade dos homens, forma "uma massa global, afetada por processos de conjunto que são próprios da vida, que são processos como o nascimento, a morte, a produção, a doença, etc.” (Foucault, 1996:209). O que significa que para além de um poder disciplinar dos corpos pelo aplicativo - o modo de vida individualizante, isto é, em relação à primeira tomada de poder que Foucault, na segunda:

o corpo que se fez consoante o modo da individualização, temos uma segunda tomada de poder que, por sua vez, não é individualizante mas que é massificante, se vocês quiserem, que se faz em direção não do homem-corpo, mas do homem-espécie. [...] vemos aparecer, uma "biopolitica" da espécie humana. (Foucault, 1996:289)

\section{CONCLUSÕES}

Ao nos voltarmos para o campo da linguagem nas e das redes sociais, conseguimos acessar parte da produção do imaginário, o que nos possibilitou compreender em que medida o uso das redes podem ser manuseadas como estratégia de poder. Sendo as redes sociais o filtro do entre-lugar para o controle dos corpos e, claro, das informações. Com base nesse estudo, podemos argumentar que é indissociável a relação entre linguagem e poder, assim como é indissociável a relação do afeto com a política. A rede social Facebook é um acontecimento histórico importante para conectar sujeitos que habitam espaços territoriais distintos, uma ferramenta útil para mobilização dos movimentos sociais (por exemplo, as jornadas de junho de 2013); mas também nos mostra a banalidade de ser sujeito nas redes, tal como pode ser um espaço de dominação e controle dos corpos, caso o seu uso passe a ser gerido por homens interessados na intensificação de seu poder. O uso das redes pelos seus usuários durante o período 


\section{Nanduty}

ISSN:2317-8590

eleitoral no Brasil, fabricou (deformou) corpos. Há, portanto, uma nova articulação, nesse período, do desejo e na subjetivação dos sujeitos sustentada pela sutileza de um novo poder (Dardot \& Laval, 2016). Há, portanto uma dessubjetivação por uma falsa ideia de subjetivação nas redes sociais.

\section{REFERÊNCIAS BIBLIOGRÁFICAS}

AGAMBEN, Giorgio. (2017). Homo Sacer: O poder soberano e a vida nua. $2^{\mathrm{a}}$ edição. Tradução: Henrique Burigo. Belo Horizonte: Editora UFMG.

BAKHTIN, Mikhail. (2016). Os gêneros do discurso. Tradução: Paulo Bezerra. Editora 34.

BAHBHA, Homi. (1998). O local da Cultura. Belo Horizonte. $2^{a}$ edição. Tradução: Myriam Ávila, Eliana Lourenço de Lima Reis, Gláucia Renate Gonçalves, Belo Horizonte. Editora UFMG.

BRUM, Eliane. (2018). O ódio deitou no meu divã. El país. Disponível em: https://brasil.elpais.com/brasil/2018/10/10/politica/1539207771_563062.html. Acesso em: 23 dez. 2018.

BUTLER, Judith \& HECKER, Jamie. (2012). Sobre o anarquismo: uma entrevista com Judith Butler. Revista de Ciências Sociais, n. 36, pp.19-27.

DE CASTRO, Eduardo Viveiros. 2017. A Inconstância da Alma Selvagem. Cultrix. Editora. Cosacnaify.

DANNER, Fernando. (2010). O Sentido da Biopolítica em Michel Foucault. In: Revista Estudos Filosóficos no 4. Versão eletrônica - ISSN 2177-2967. São João del-Rei-MG.

DARDOD, Pierre \& LAVAL Chistian. (2017). A fábrica do sujeito neoliberal, In: A nova razão do mundo: Ensaio sobre a sociedade neoliberal. Edição: Boitempo. Tradução: Mariana Echalar. São Paulo.

FOUCAULT, Michel. (2016). As Palavras e as Coisas: Uma Arqueologia das Ciências Humanas. 10 $0^{\mathrm{a}}$ Edição. Tradução: Salma Tannus Muchail. Editora: Martins Fontes. São Paulo.

(1996). Segurança, Território e População. $1^{a}$ edição. Tradução: Eduardo Brandão. São Paulo. Editora: Martins Fontes.

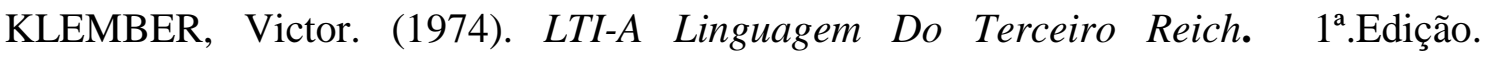
Tradução: Miriam Bettina P. Oelsner .Editora: Contraponto. São Paulo.

LEVI-STRAUSS, Claude. (1975). Antropologia Estrutural. 10a. Edição. Tradução: Chaim Samuel Katz e Eginardo Pires ; revisão etnológica de Júlio Cezar Melatti. Editora: Tempos Brasileiros. Rio de Janeiro.

SAFATLE, Vladimir. (2015). O circuito dos afetos: Corpos políticos, desamparo e o fim do indivíduo. $2^{\text {a }}$ edição Editora: Autêntica.

SAUSSURE, Ferdinand de. (1989). Curso de Linguística Geral. Edição: 27ª Tradução: Antônio Chelini, José Paulo Paes e Izidoro Blikstein.Editora: Cultrix. São Paulo. 